\title{
Prosthodontic Management of Patient with Anterior Hyperfunction Syndrome: A Clinical Challenge
}

Sanjan Verma ${ }^{1}$ Manjit Kumar ${ }^{1}$ Ritu Batra ${ }^{1}$ Chhavi Sharma ${ }^{1}$ Shak Mehta ${ }^{1}$
Address for correspondence Manjit Kumar, MDS, Department of Prosthodontics, Bhojia Dental College and Hospital, Baddi 173205 , Distt. Solan, Himachal Pradesh, India (e-mail: manjitkiran@yahoo.co.in).

\begin{abstract}
Keywords

- anterior hyperfunction

- combination syndrome

- distal-extension removable partial denture

The patient with complete edentulous maxillary arch and partially edentulous mandibular arch poses certain complication in the form of syndrome which was described by Kelly in 1972. There is flabby tissue in the anterior maxilla and posterior occlusal plane slope-down. There is supraeruption of lower anterior teeth, fibrous growth of tuberosity area, resorption of bone in the posterior mandibular ridges, and loss of vertical dimension of occlusion. The treatment varies from patient to patient to develop this syndrome and also varies from condition of the remaining teeth. Best treatment option is to use dental implants, but conventional prostheses are used in complex cases. This clinical report presents the prosthetic rehabilitation of a patient exhibiting combination syndrome.
\end{abstract}

\section{Introduction}

Prosthodontic rehabilitation of a case with completely edentulous maxilla opposing partial mandibular arch poses many challenges for a clinician. There is anterior bone loss in the maxilla and supraeruption of the lower anterior teeth. For this oral condition, Kelly (1972) proposed the term "combination syndrome." "Glossary of Prosthodontic Terms" GPT (9), (2017) $)^{2}$ defined combination syndrome as the characteristic features of complete edentulous maxilla with opposed partial edentulous mandible, leading to loss of bone in the anterior maxillary region, overgrowth of the tuberosity area, papillary hyperplasia of the hard palatal mucosa, supraeruption of the lower anterior teeth, and loss of bone in the mandibular posterior region. This is also known as anterior hyperfunction syndrome. Therefore, according to Kelly, posterior teeth should be preserved to provide stable occlusion for lower removable partial denture (RPD), thus avoiding combination syndrome. To avoid this complex condition, preservation of posterior occlusion is of utmost importance.

Saunders et al (1979) ${ }^{3}$ and Jameson $(2001)^{4}$ advocated use of linear occlusion concept, using alternative tooth form to reduce anterior hyperfunction. There should be maximum area coverage of distal-extension base with minimum contact in eccentric position of the mandible.

Best treatment option is to place implants in edentulous areas and resolve occlusion with implant-supported prostheses, so that even occlusal force distribution is achieved to prevent resorption and stresses on the bone. ${ }^{5}$

This clinical report represents the prosthodontic management of a specific case of combination syndrome.

\section{Case Report}

A 62-year-old male patient reported to the Department of Prosthodontics, Bhojia Dental College and Hospital, Baddi, Himachal Pradesh, with chief complaint of loose maxillary complete denture and difficulty in chewing. There was no medical history or history of drug allergy. On examination, the patient revealed all teeth missing in maxillary area. Lower anterior nine teeth were present. There were loss of bone in the anterior maxillary area, overgrowth of the maxillary tuberosity bilaterally, and supraeruption of lower anterior teeth (-Fig. $\mathbf{1}$ ).

\section{received}

September 26, 2018

accepted after revision

November 30, 2018

published online

January 8, 2019
DOI https://doi.org/

10.1055/s-0038-1677647

ISSN 2321-1482.
C2018 Bhojia Dental College and Hospital affiliated to Himachal Pradesh University
License terms

(ㅇ) (1) $\ominus \circledast$ 
The patient was motivated and educated for oral hygiene measure, caries control, and periodontal therapy. Upper preliminary impressions were made with impression compound (Rolex, Delhi, India), lower irreversible hydrocolloid materials (Zhermack, Badia Polesine, Italy), and poured with dental stone (Kalabhai, Mumbai, India).

A custom tray was fabricated with a wax relief in anterior hypermobile tissue. Border molding was recorded using green modeling compound (DPI, Delhi, India). Final impression was made with zinc oxide eugenol impression material (DPI, Delhi, India) (- Fig. 2).

Diagnostic cast was surveyed. Then planned mouth preparation was done, and the definitive impression of

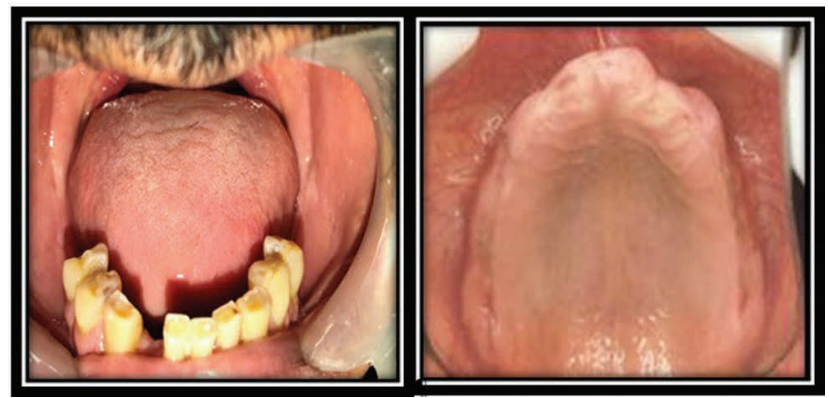

Fig. 1 Intraoral view.

the RPD framework was made with C-silicone material (Zetaplus, Badia Polesine, Itlay) (-Figs. 3, 4). The altered-cast technique was used for the formation of cast partial denture, and final impression was made (-Fig. 5).

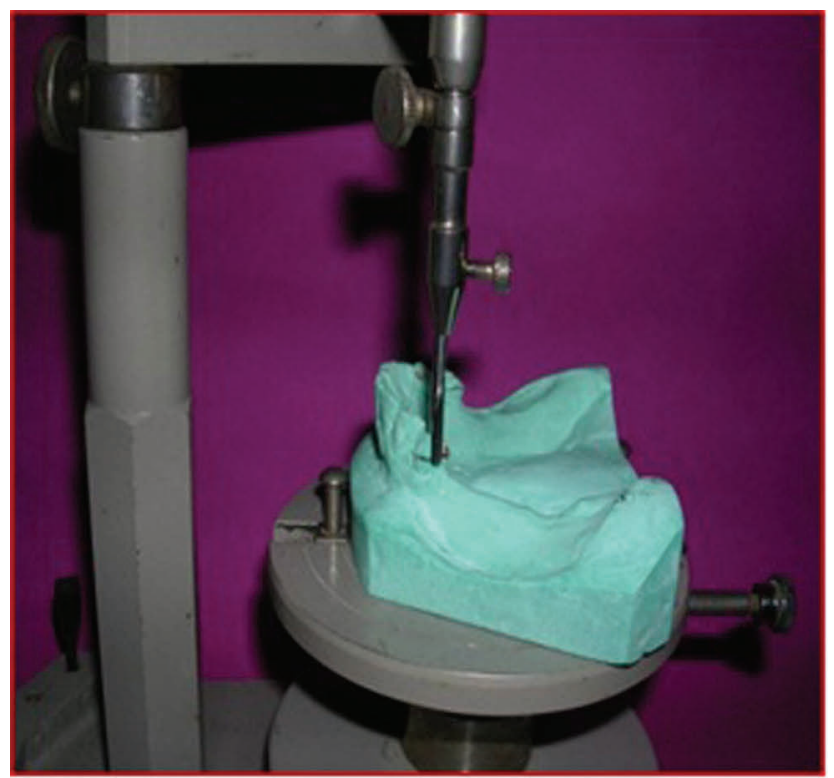

Fig. 3 Surveying of master cast.
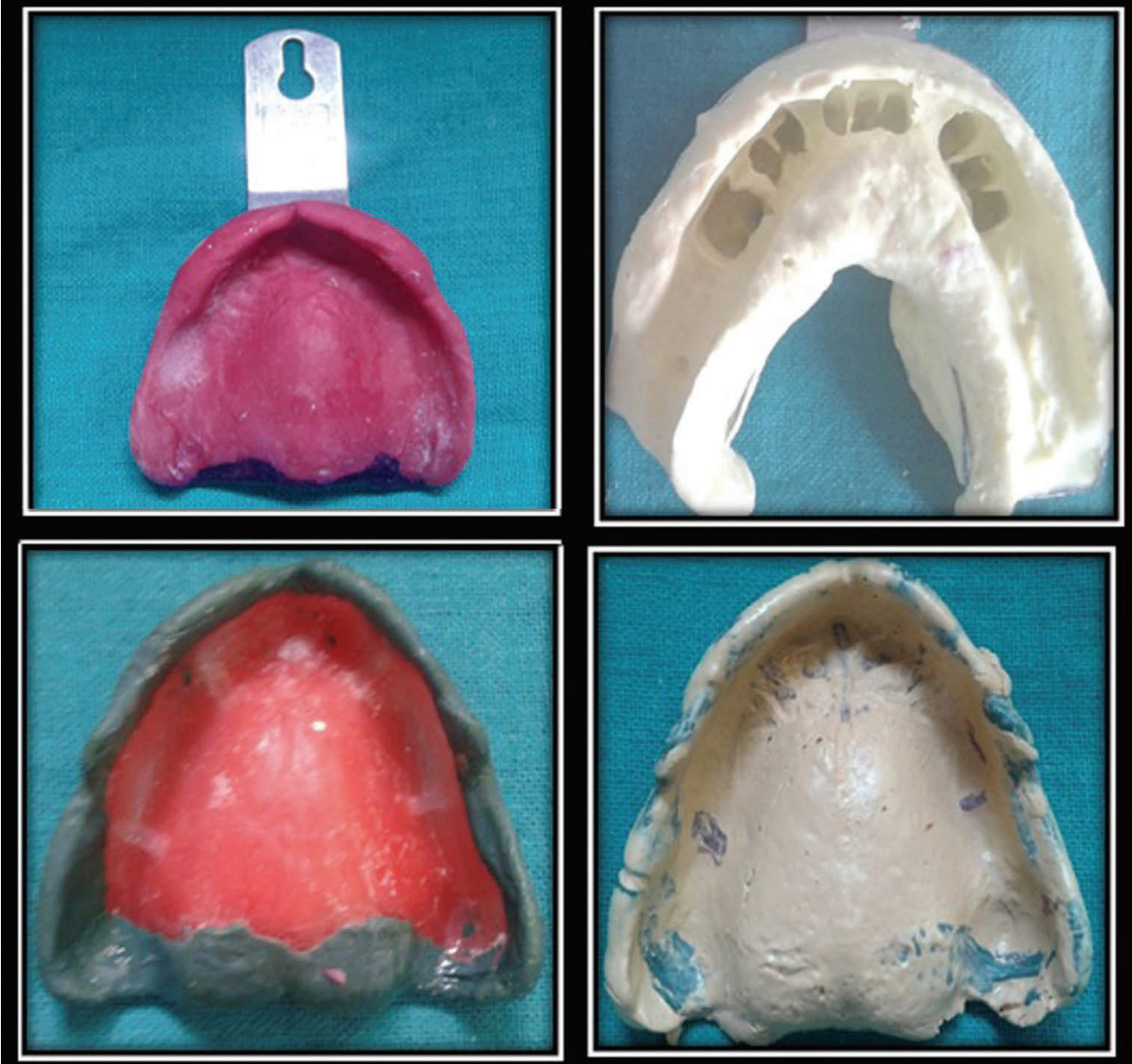

Fig. 2 Preliminary and final impression. 
Anterior teeth selection was done according to patient sex and personality.

Balanced occlusion scheme was incorporated to balance occlusal force and prevent occlusal interferences in various excursive movements of mandible during chewing procedure. Dentures were adjusted and occlusal adjustment was done ( - Figs. $\mathbf{6}, \mathbf{7}$ ). The patient was satisfied from

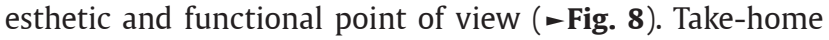
instruction was given to the patient as maintenance phase therapy. On recall visit after 18 months, no complications were observed ( - Fig. 9).

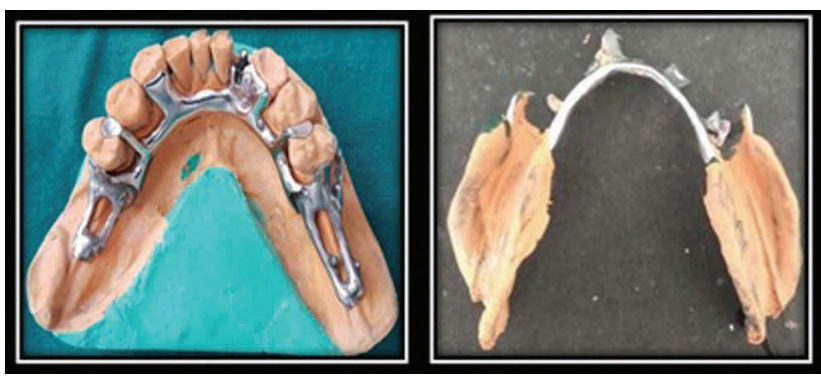

Fig. 4 Master cast with cast partial framework and mandibular final impression.

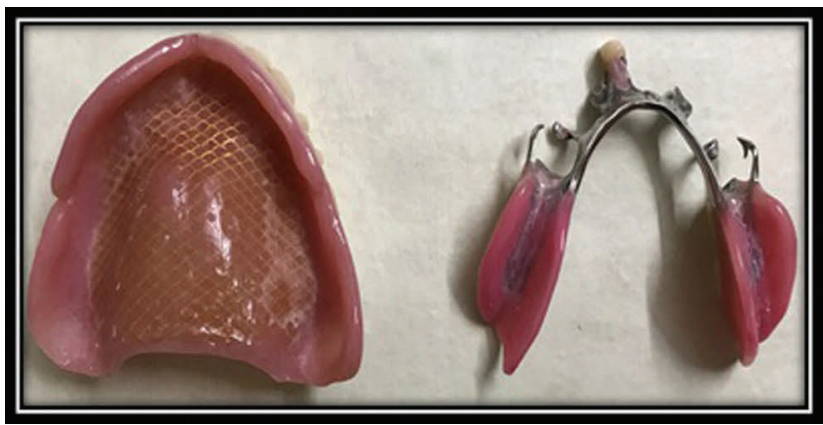

Fig. 6 Complete maxillary denture.

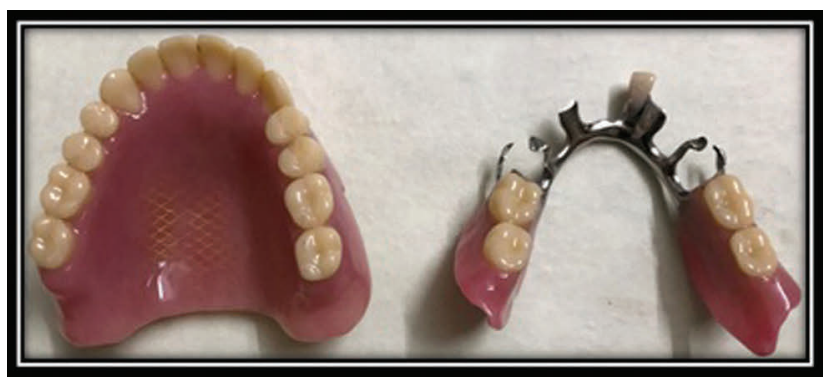

Fig. 7 Mandibular complete denture.
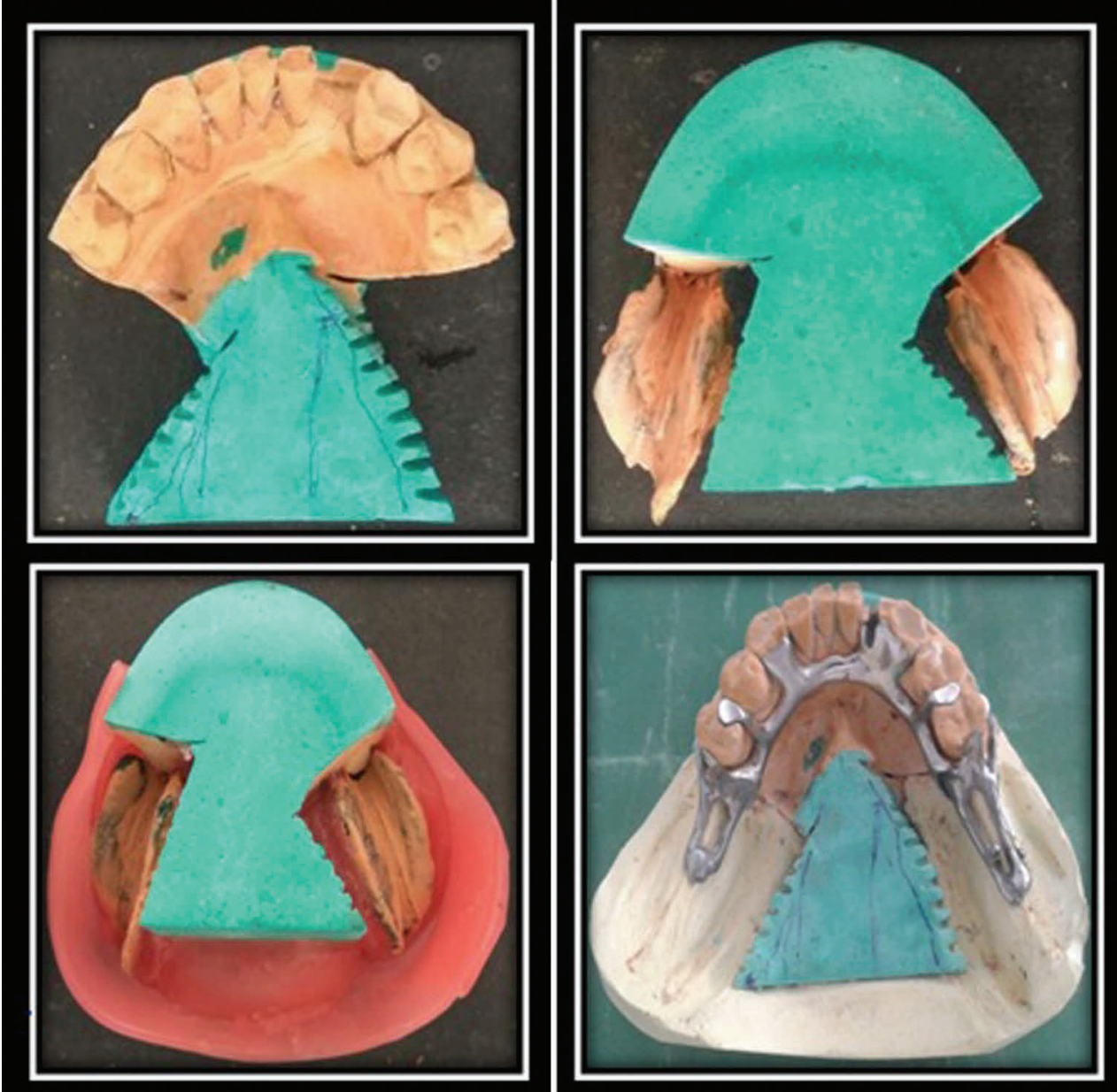

Fig. 5 Altered cast technique. 


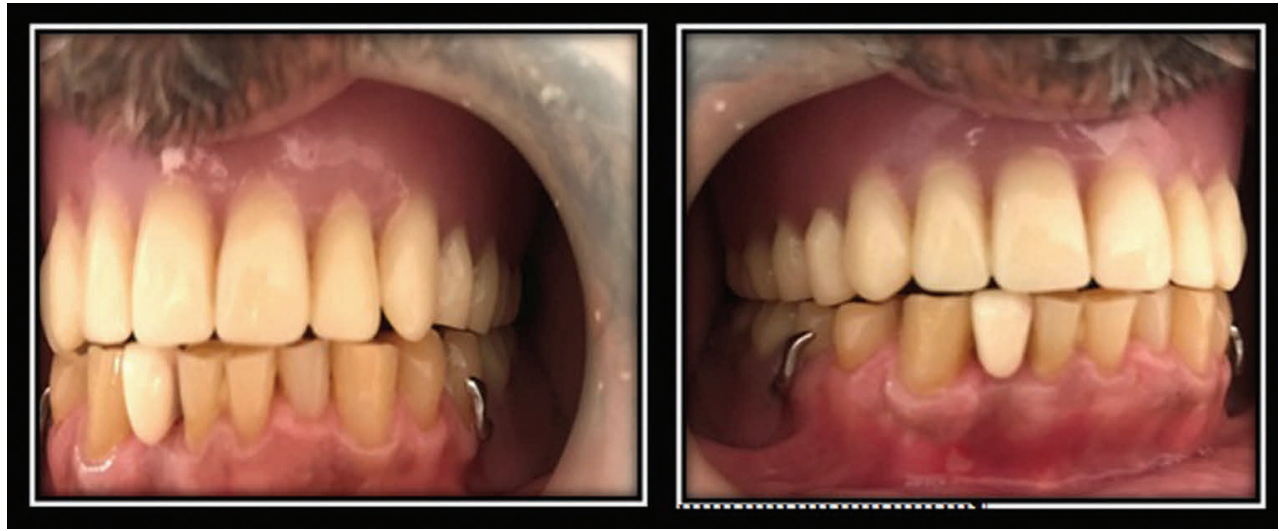

Fig. 8 Intraoral view after insertion.
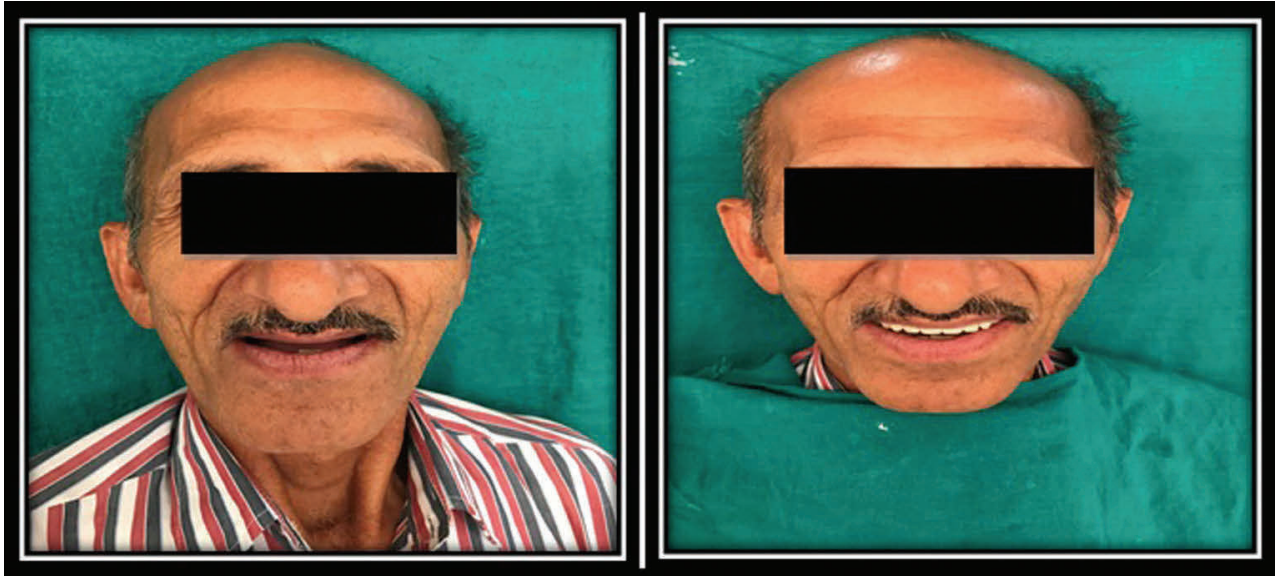

Fig. 9 Pre- and postoperative view.

\section{Discussion}

Prosthodontic rehabilitation of the patient with all missing maxillary teeth and lower posterior teeth by giving upper complete denture and posterior lower partial denture poses a challenge to most clinicians. There is $24 \%$ prevalence of such syndrome. Treatment of patients with an edentulous maxilla opposed to natural mandibular anterior teeth and a distal-extension RPD is considered a challenge for dental practitioners. Combination syndrome has a prevalence rate of approximately $24 \%$ for denture patients. ${ }^{6}$ Therefore, treatment plan has to be fabricated according to particular complaints of patients. If pressure is applied in anterior region of the maxilla and there is less contact in the posterior region, it may lead to further complication. ${ }^{7}$ Kelly reported $0.43 \mathrm{~mm} /$ year alveolar bone resorption in the upper anterior region. Lopaz-Rolden et al $(2009)^{8}$ and Barber et al $(1990)^{9}$ also showed similar result. There is $0.32 \mathrm{~mm} /$ year and $0.36 \mathrm{~mm} /$ year bone loss among the patients wearing maxillary complete denture and mandibular implant retained overdentures.

Maximum extension of denture bases, preservation of the mandibular posterior teeth and avoiding pressure on anterior region of the maxilla lead to less bone loss. Similarly, Van Waas et al $(1993)^{10}$ suggested root preservation technique and preparation of overdenture, rather than complete extraction and fabrication of balance complete denture.

Without disturbing the flabby tissue in anterior area of the maxilla, mucostatic impression was made to record maximum denture-bearing area, and for better stress distribution occlusal scheme was modified for balanced occlusion in various mandibular movements. The effect of edentulous mandible and retained mandibular teeth on edentulous maxilla was discussed and investigated.

Carlsson et al (1967) ${ }^{11}$ compared bone resorption in cases of maxillary complete denture as opposed by three different mandibular conditions: (1) a mandibular complete denture; (2) mandibular anterior teeth with bilateral extension RPD; and (3) mandibular teeth only. Less bone resorption was found in cases having mandibular intact teeth as compared with partially edentulous mandible with or without partial dentures. However, less bone resorption in patients with a maxillary complete denture was opposed by a bar-retained mandibular RPD. ${ }^{12}$

Other studies ${ }^{13,14}$ showed no significant differences, but individual variations were larger. However, the experimental data revealed that greater bone resorption occurred among patients with unilateral or bilateral RPD. For better prognosis of combination syndrome, implant-retained prosthesis in the mandibular posterior area is recommended to avoid negative roll of distal extension RPD. ${ }^{15}$ 


\section{Conclusion}

To prevent anterior hyperfunction, avoid extraction with upper posterior teeth. In case of anterior hyperfunction or combination syndrome, mucostatic impression technique with less pressure on the anterior maxillary region and balanced occlusion is necessary to avoid failure and any other complication.

\section{Conflict of Interest}

None declared.

\section{References}

1 Kelly E. Changes caused by a mandibular removable partial denture opposing a maxillary complete denture. J Prosthet Dent 1972;27(2):140-150

2 The glossary of prosthodontic terms. J Prosthet Dent 2005;94(1):10-92

3 Saunders TR, Gillis RE Jr, Desjardins RP. The maxillary complete denture opposing the mandibular bilateral distal-extension partial denture: treatment considerations. J Prosthet Dent 1979;41(2):124-128

4 Jameson WS. The use of linear occlusion to treat a patient with combination syndrome: a clinical report. J Prosthet Dent 2001;85(1):15-19

5 Tolstunov L. Management of biomechanical complication of implant-supported restoration of a patient with combination syndrome: a case report. J Oral Maxillofac Surg 2009;67(1):178-188

6 Shen K, Gongloff RK. Prevalence of the "combination syndrome" among denture patients. J Prosthet Dent 1989; 62(6):642-644
7 Palmqvist S, Carlsson GE, Owall B. The combination syndrome: a literature review. J Prosthet Dent 2003;90(3):270-275

8 López-Roldán A, Abad DS, Bertomeu IG, Castillo EG, Otaolaurruch ES. Bone resorption processes in patients wearing overdentures. A 6-years retrospective study. Med Oral Patol Oral Cir Bucal 2009;14:203-209

9 Barber HD, Scott RF, Maxson BB, Fonseca RJ. Evaluation of anterior maxillary alveolar ridge resorption when opposed by the transmandibular implant. J Oral Maxillofac Surg 1990;48(12):1283-1287

10 Van Waas MA, Jonkman RE, Kalk W, Van 't Hof MA, Plooij J, Van Os JH. Differences two years after tooth extraction in mandibular bone reduction in patients treated with immediate overdentures or with immediate complete dentures. J Dent Res 1993;72(6):1001-1004

11 Carlsson GE, Bergman B, Hedegård B. Changes in contour of the maxillary alveolar process under immediate dentures. A longitudinal clinical and $x$-ray cephalometric study covering 5 years. Acta Odontol Scand 1967;25(1):45-75

12 Uçtaşli S, Hasanreisoğlu U, Işeri H. Cephalometric evaluation of maxillary complete, mandibular fixed-removable partial prosthesis: a 5-year longitudinal study. J Oral Rehabil 1997;24(2):164-169

13 Crum RJ, Rooney GE Jr. Alveolar bone loss in overdentures: a 5-year study. J Prosthet Dent 1978;40(6):610-613

14 Tallgren A. The continuing reduction of the residual alveolar ridges in complete denture wearers: a mixed-longitudinal study covering 25 years. J Prosthet Dent 1972;27(2):120-132

15 Keltjens HM, Kayser AF, Hertel R, Battistuzzi PG. Distal extension removable partial dentures supported by implants and residual teeth: considerations and case reports. Int J Oral Maxillofac Implants 1993;8(2):208-213 